${ }^{17}$ Stamm WE, Wagner KF, Amsel R, et al. Causes of the acute urethral syndrome in women. $N$ Engl f Med 1980;303:409-15.

18 Paavonen J. Chlamydia trachomatis-induced urethritis in female partners of men with nongonococcal urethritis. Sex Transm Dis 1979;6:69-71.

19 Tait IA, Rees E, Jameson RM. Urethral syndrome associated with chlamydial infection of the urethra and cervix. BrF Urol 1978;50:425.

20 Curran JW. Gonorrhoea and the urethral syndrome. Sex Transm Dis $1977 ; 4: 119-21$.

${ }^{21}$ Farrar DJ, Green NA, Ashken MH. An evaluation of Otis urethrotomy in female patients with recurrent urinary tract infections. Br f Urol 1973; 45:610-5.

22 Splatt AJ, Weedon D. The urethral syndrome: experience with the Richardson urethroplasty. Brf Urol 1977;49:173-6.

${ }^{23}$ Richardson FH, Stonington OG. Urethrolysis and external urethroplasty in the female. Surg Clin North Am 1969;49:1201-8.

24 Hendry WF, Stanton SL, Williams DI. Recurrent urinary infections in girls : effects of urethral dilatation. $B r \mathcal{F}$ Urol 1973;45:72-83.

${ }^{25}$ Kaplan GW, Sammons TA, King LR. A blind comparison of dilatation, urethrotomy and medication alone in the treatment of urinary tract infection in girls. $\mathcal{F}$ Urol 1973;109:917-9.

26 Rees DLP, Whitfield HN, Islam AKMS, Doyle PT, Mayo ME, Wickham JEA. Urodynamic findings in adult females with frequency and dysuria. BrF Urol 1975;47:853-60.

27 Anonymous. Urethral syndrome. Br Med f 1968 ;ii: 192.

28 Anonymous. The urethral syndrome. Br Med F 1977;ii :593-4.

29 Asscher AW. Use of antibiotics: management of frequency and dysuria. Br Med f 1978;i :1531-3.

\section{Recurrent renal calculi}

Around $2-3 \%$ of people in Western countries suffer an attack of renal colic due to renal calculi. The risk of recurrence after the first episode is between $20 \%$ and $50 \%$ over a follow-up period of 10 years. ${ }^{1}$ In Britain $80 \%$ of calculi are composed of calcium oxalate or phosphate or both, and recurrence is likely in patients with known underlying causes such as idiopathic hypercalciuria, medullary sponge kidney, primary hyperparathyroidism, renal tubular acidosis, or primary hyperoxaluria. Unfortunately, no such cause is discovered in one-third or more of patients with calcium stones.

Recurrence rates have fallen in the past decade with improvement in the medical management of known metabolic abnormalities. Urinary calcium excretion may be reduced in idiopathic hypercalciuria by giving either orthophosphates, ${ }^{2}$ sodium cellulose phosphate (which binds calcium in the gastrointestinal tract), ${ }^{3}$ or thiazides. ${ }^{4}$ Yendt and Cohanim ${ }^{4}$ have claimed that the recurrence rate in patients with idiopathic hypercalciuria can be cut by as much as $90 \%$. Recently, allopurinol has also been shown to be effective in reducing the recurrence rate of renal calculi in hypercalciuric states, and especially in patients with hyperuricosuric calcium oxalate stones. ${ }^{5}$ Other effective treatments include surgery for primary hyperparathyroidism or giving alkalis to patients with renal tubular acidosis.

Despite these measures, some patients still have recurrences of their renal calculi. Repeated attacks of severe pain may lead to narcotic addiction, while renal function may be impaired by intrarenal or extrarenal obstruction with or without urinary tract infection. Damage to the ureters may exacerbate the problems due to obstruction, as may the aftermath of surgical procedures such as pyelolithotomy, ureterolithotomy, and partial nephrectomy.

Various surgical methods such as ileal transposition have been devised to circumvent some of these complications. Some 20 years ago Goodwin and his colleagues ${ }^{6}$ first noted that free calculi in a kidney "silently" disappeared after operation in a patient treated with an ileal transposition for a severely damaged ureter. Since then, this method has been used in many patients; the wide bore of the ileal ureter permits the free passage of calculi into the bladder. There are, however, longterm disadvantages from this operation-apart from a high incidence of operative complications. The ileal mucosa retains its reabsorptive qualities, so that hyperchloraemic acidosis tends to develop from increased reabsorption of ammonia and chloride, and this may aggravate an already existing acidotic state from underlying chronic pyelonephritis. Urinary tract infection and vesicoureteric reflux are common and may further reduce renal function.?

An ingenious alternative, recently described, is renal autotransplantation, which appears to have many advantages. ${ }^{8}$ Renal autotransplantation, which has been used for patients with tumours in single kidneys ${ }^{9}$ and renovascular hypertension, ${ }^{10}$ is performed by transplanting the kidney into the iliac fossa and creating a bladder flap for the ureter, so permitting easy passage of any calculi into the bladder. Four such operations have been reported in three patients, two with medullary sponge kidney and another with idiopathic hypercalciuria. The surgeons report no postoperative complications, with all kidneys functioning immediately. All three patients have become free of symptoms, and two who had become narcotic addicts were cured of their habit. On long-term follow-up there was no evidence of urinary tract infection, and in only one of the four transplanted kidneys was there any vesicoureteric reflux. No electrolyte disturbances were encountered and renal function has been well maintained within normal limits over six years. If further results are equally encouraging renal autotransplantation may become the definitive procedure for patients with recurrent renal calculiprovided it is performed by surgeons with adequate experience of renal transplantation.

1 Williams RE. Long-term survey of 538 patients with upper urinary tract stones. Br $\mathcal{F}$ Urol 1963 ;35:416-37.

2 Ettinger B, Kolb FO. Inorganic phosphate treatment of nephrolithiasis. Am f Med 1973;55:32-7.

${ }^{3}$ Pak CYC, Delea CS, Bartter FC. Successful treatment of recurrent nephrolithiasis (calcium stones) with cellulose phosphate. $N$ Engl f Med 1974; 290:175-80.

4 Yendt ER, Cohanim M. Prevention of calcium stones with thiazides. Kidney Int 1978;13:397-409.

5 Coe FL. Treated and untreated recurrent calcium nephrolithiasis in patients with idiopathic hypercalciuria, hyperuricosuria or no metabolic disorder. Ann Intern Med 1977;87:404-10.

- Goodwin WE, Winter CC, Turner RD. Replacement of the ureter by small intestine: clinical application and results of the "ileal ureter." $F$ Urol $1959 ; 81: 406-18$

7 Tanagho EA. A case against incorporation of bowel segments into the closed urinary system. $\mathcal{F}$ Urol $1975 ; 113: 796-802$.

8 Olsson CA, Idelson B. Renal autotransplantation for recurrent colic. $7 \mathrm{Urol}$ $1980 ; 123: 467-73$.

- Calne RY. Treatment of bilateral hypernephromas by nephrectomy, excision of tumour and autotransplantation. Report of three cases. Lancet 1973; ;i: 116-67.

${ }^{10}$ Clunie GJA, Hartley LCJ, Collins GM, Gordon RD. Renovascular hypertension: the place of renal autotransplantation. Br f Surg 1973; $60: 562-4$

\section{Correction}

\section{The risks of assessing risks}

We regret that an ambiguous sentence appeared in the fourth paragraph of our leading article on the risks of assessing risks (22 November, p 1374). "No human data are better than indifferent data," was intended to mean that all human data are indifferent; not that it is better to have no data at all than the necessarily indifferent human data. 